\title{
Estimation of Vertical Mixing Based on Water Current Monitoring in the Hypolimnion of Lake Biwa*
}

\author{
Yasuaki AOTA* $^{* *}$, Michio KUMAGAI ${ }^{* * *}$ and Kenji KASHIWAYA**
}

\begin{abstract}
Using continuous monitoring data over last two years in the North Basin of Lake Biwa, we showed the time change of water currents and temperature from May 2003 to May 2005. Two acoustic current meters (ACMs) were deployed at $1.8 \mathrm{~m}$ and $54 \mathrm{~m}$ height from lake bottom respectively, at the observation point with the depth of $90 \mathrm{~m}$ near the deepest place $(104 \mathrm{~m}$ depth). We measured horizontal current velocity, current direction, and water temperature at every 20 minutes, and estimated the bottom stress with horizontal current velocity and water temperature. Average water current velocity near the lake bottom through the observation was weak as reported before, however, maximum current velocity due to strong typhoon in October 2004 reached almost $30 \mathrm{~cm} / \mathrm{s}$. Moreover, comparatively strong water current velocity was observed from January to February in each winter. The estimation of the bottom stress with current velocity suggested us that strong currents could re-suspend bottom sediments.
\end{abstract}

Key Words: Boundary Layer, Flow Measurements, Turbulent Mixing, Lake Biwa, Continuous Monitoring, Bottom Current

\section{Introduction}

In the North Basin of Lake Biwa, a large number of study on water currents has been conducted to investigate water current structure and its life, concerned with environmental issues of water quality due to eutrophication, from the viewpoints of field observations, laboratory experiments and model analyses. Especially, the gyres have been well studied since $1926^{(1)}$, and recently their seasonal distributions were precisely observed by using ADCP (Acoustic Doppler Current Profiler) ${ }^{(2)}$. In the deep area in the North Basin of Lake Biwa, some influences caused by global warming were reported, for example, the increase of average water temperature ${ }^{(3)}$, and the decrease of dissolved oxygen ${ }^{(4)}$ during last 30 years. These environmental rapid changes in the hypolimnion still require to monitor the water currents, to measure water quality for a long-term, and then to clarify the vertical mixing processes of the lake water induced by strong wind, and the sediment-water interaction mechanism.

Water currents have not been measured so much in

* Received 13th March, 2006 (No. 06-4059)

** Institute of Nature and Environmental Technology, Kanazawa University, Kakuma, Kanazawa, Ishikawa 9201192, Japan. E-mail: yaota@kenroku.kanazawa-u.ac.jp

*** Lake Biwa Environmental Research Institute, 5-34 Yanagasaki, Otsu, Shiga 520-0022, Japan the deep layers of Lake Biwa as in the shallow layers, and little data were available for a long-term over one year. In the studies for past several decades, the deep area of the lake was considered extremely still, and there were weak currents. Kumagai $^{(6)}$ observed water current near the bottom boundary layer at the deepest point of the North Basin of Lake Biwa by using the 3-dimensional acoustic current meter, and calculated the shear stress on the lake bottom. Two observations were performed near the deepest point under weak wind speed for two weeks, and, both of them showed that weak currents about $2 \mathrm{~cm} / \mathrm{s}$ were dominant during the observation period. Therefore, bottom shear stress was not as high as it can cause resuspension of the bottom sediments ${ }^{(6)}$. On the other hand, in 1985, Okumura and Endoh ${ }^{(5)}$ observed the wide area around the first gyre including the deepest point for one year in total, and showed the relatively strong currents $(10-15 \mathrm{~cm} / \mathrm{s})$. Also, Okumura and Endoh ${ }^{(7)}$ measured bottom water currents continuously at the southern part in the North Basin of Lake Biwa for one year. They showed the existence of the periodical current with long period caused by internal wave as previously reported ${ }^{(8)}$.

If strong wind such as typhoon may create large shear stress near the bottom of Lake Biwa, subsequently may enhance vertical flux of the sediments in the lake bottom. That is why, it could be important to estimate friction velocity and shear stress working on the lake bottom based 
on the long-term monitoring data.

Friction velocity and shear stress on the lake bottom boundary have been recently estimated from the multiple layer current measurements in the vertical water body by using ADCP in oceans. In lakes, Lorke et al. ${ }^{(9)}$ and Lars and Urich ${ }^{(10)}$ calculated the friction velocity at Lake Alpnach and Lake Geneva, respectively. In the past studies, Kumagai $^{(6)}$ and Gloor et al. ${ }^{(11)}$ estimated the friction velocity by using ACM (Acoustic Current Meter), which can measure water currents at a single point. In this case, the area that can be measured is limited, but easy to use for long-term estimation and accuracy of ACM is higher than that of ADCP.

As Okumura and Endoh ${ }^{(7)}$ stated, it is not easy to monitor continuously water currents or temperature at the deep point in the lake for a long time over one year, because human being disturbances such as fishery occur frequently. In this paper, we report the results of two year monitoring of the water currents at the deepest point in the lake from 2003 to 2005 . Then, we calculate friction velocity and stress on the lake bottom with the observed current data, and show the fluctuation of the water near the lake bottom.

\section{Method}

\subsection{Instruments and study site}

We deployed two ACM8Ms, which are a memory type magnetic current meters (ACM) manufactured by Alec Electronics Co., Ltd., near the deepest point in the North Basin of Lake Biwa (Fig. 1). Water depth of the site was about $90 \mathrm{~m}$ from lake surface, and the observation site is located near Ado-Gawa River, which has a 3rd largest catchment area in the so called first-grade rivers around the lake. Two ACMs were set on the point of $1.8 \mathrm{~m}$ and $54 \mathrm{~m}$ heights, respectively, from the lake bottom (Fig. 2), and measured horizontal current vector and water temperature. The accuracy of water currents and temperature measured by ACMs is $0.5 \mathrm{~cm} / \mathrm{s}$ and $0.02^{\circ} \mathrm{C}$, respectively. Monitoring started from May 21 in 2003, and measured every 20 minutes interval. Measured current data were averaged for 30 data sampled every 0.5 seconds in each measurement. Water temperature measurement was set only 1 time every 20 minutes because of the limitation of the data logger capacity. Figure 2 shows sediment traps for collecting sediment as well, but we did not deal with them in this paper. The field observations were carried out by the R/V "Hakken" of the Lake Biwa Environmental Research Institute. All data of the wind velocity was obtained from Hikone Local Meteorological Observatory. The accuracy of the anemometer is $0.5 \mathrm{~m} / \mathrm{s}$ when wind velocity is weaker than or equal to $10 \mathrm{~m} / \mathrm{s}$, and $5 \%$ when wind velocity exceeds $10 \mathrm{~m} / \mathrm{s}$.

\subsection{Data processing}

The data measured by ACM were collected every 2-

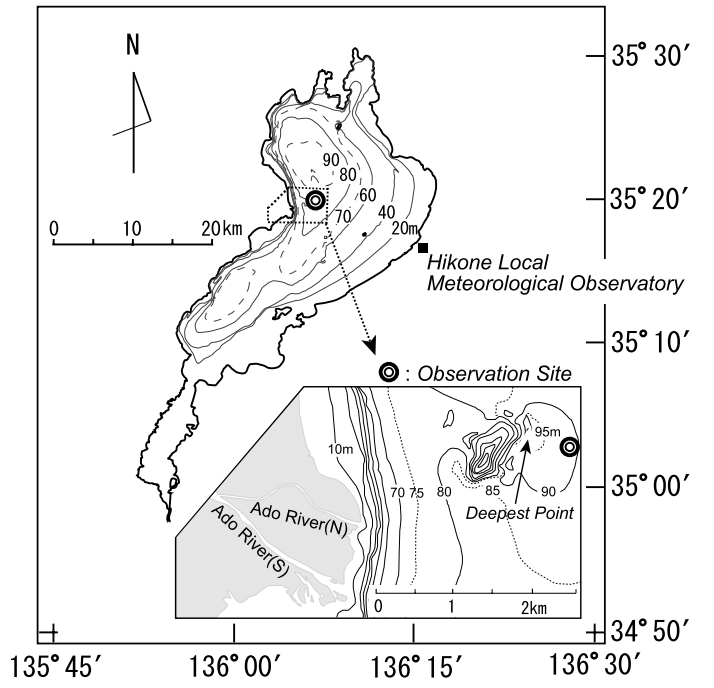

Fig. 1 Observation site in Lake Biwa

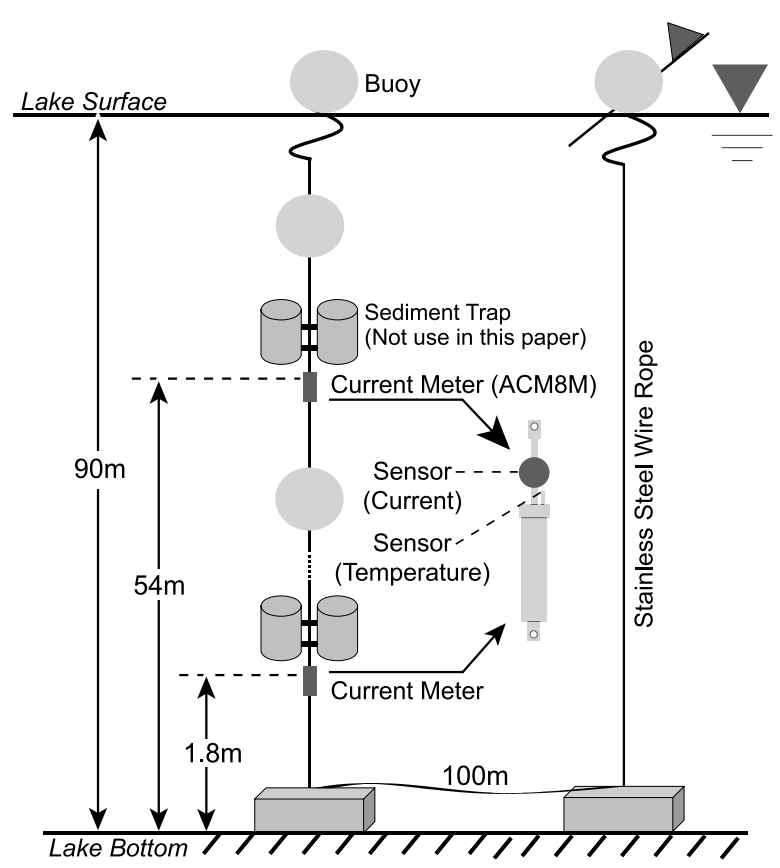

Fig. 2 Mooring system

month, but other equipments such as traps, which were attached on the same mooring system, were collected every 1-month. Therefore, the mooring system was lifted up every 1-month. We removed the data during recovery as the error data. In the measured data, small number of data (about $0.01 \%$ of all data) showed the unexpected value (all zero data, or large current velocity greater than $100 \mathrm{~cm} / \mathrm{s}$ ). These data were also removed as abnormal data. After removing these data, we interpolated the lost data with $20 \mathrm{~min}$ intervals. Unfortunately, ACM deployed at $1.8 \mathrm{~m}$ above the lake bottom stopped from March 12 to 22 in 2004, because the battery ran down, and we could not deploy ACM at $54 \mathrm{~m}$ above the bottom from September 20 to August 23 in 2004 because of instrument trouble. 
Both lost periods were longer than 10 days, and we dealt with them as lost data period without any interpolation. Furthermore, the current data of ACM deployed at $1.8 \mathrm{~m}$ above the lake bottom showed very large fluctuation from April 24 to May 17 in 2005. During this observation period, any disturbance might be caused by other factors, because some trouble was found when ACM was exchanged. Therefore, we did not deal with the data during this period.

\subsection{Estimation of friction velocity and stress on the} lake bottom

To estimate the friction velocity and stress, it is important to define the distance of the sensor position from the bottom. However, it is difficult to define the bottom surface in the natural state. The anchor weight of the mooring system has square shape, and it might be buried in the bottom sediment. So, we define the height of the sensor position as the distance from the surface of the square weight to the sensor. According to the previous study ${ }^{(6)}$, the sensor position could be regarded as being near or in the turbulent boundary layer. Therefore, we assumed that this layer approximately is in the turbulent boundary layer.

In the turbulent boundary layer, "law-of the wall" is applied as the following equation:

$$
\frac{<u(z)>}{u_{*}}=\frac{1}{\kappa} \ln \frac{u_{*} z}{v}+C,
$$

where, $\langle u(z)>$ is time average of the horizontal velocity $u(z)$ at the vertical distance $z(=1.8 \mathrm{~m})$ from bottom surface. $u_{*}$ denotes friction velocity. $\kappa$ and $v$ represents Kármán's constant and kinematic viscosity, respectively, which are given by 0.4 and the value estimated from water temperature. Semiempirical value $C$ is given by constant value, 5.5. In the observation by ACM, current velocities were averaged for 30 data sampled every 0.5 seconds in each measurement. Therefore, we regarded these data as the averaged value of $u(z)$. We used Newton Method for calculating $u_{*}$ from the above equation. The bottom stress $\tau$ is defined as $\rho u_{*}^{2}$, where $\rho$ is a density of the water estimated from water temperature.

\section{Results and Discussion}

We show absolute value of horizontal water current vector and water temperature during 2-years observation calculated by running mean over 24 hours, from May 2003 to May 2005 (Figs. 3 and 4). Each figure represents the observation at upper (bottom) layer on the upper (lower) panel during just 1-year. As shown in the previous study ${ }^{(3)}$, water current in the bottom boundary layer was comparatively weak compared with the current in the upper layer, and water current in both layers was relatively strong from January to February (lower panel on Figs. 3 and 4). From January to February, relatively strong wind blew (Fig. 5), and there were no difference of the water temperature between upper and bottom layer be-

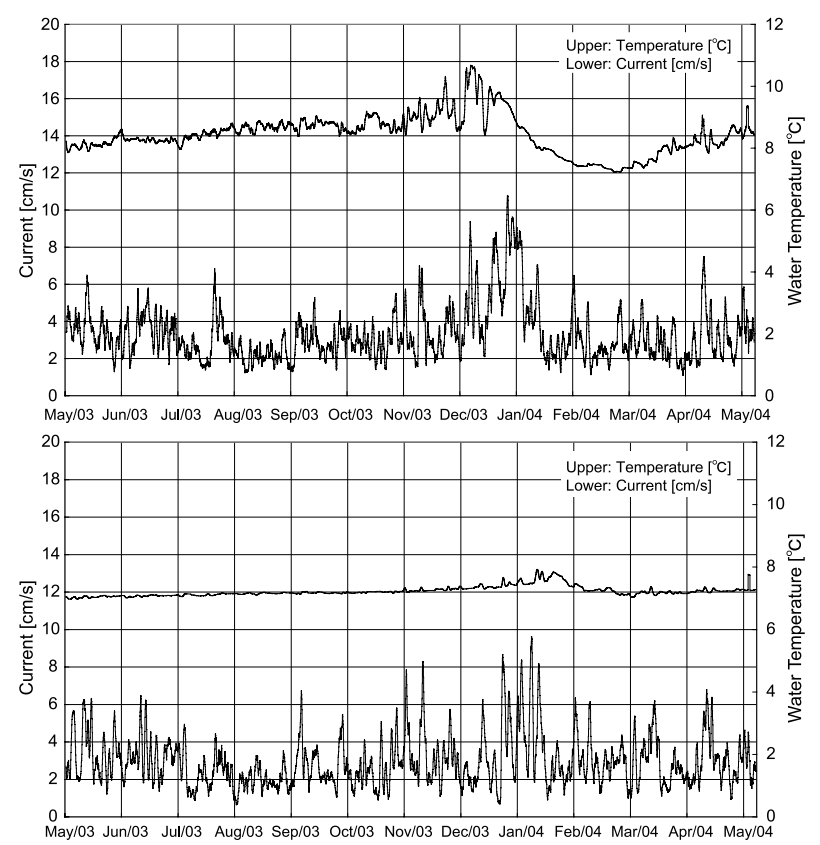

Fig. 3 Water current velocity and temperature calculated from running mean over 24 hours in each ACM (from May 2003 to May 2004)

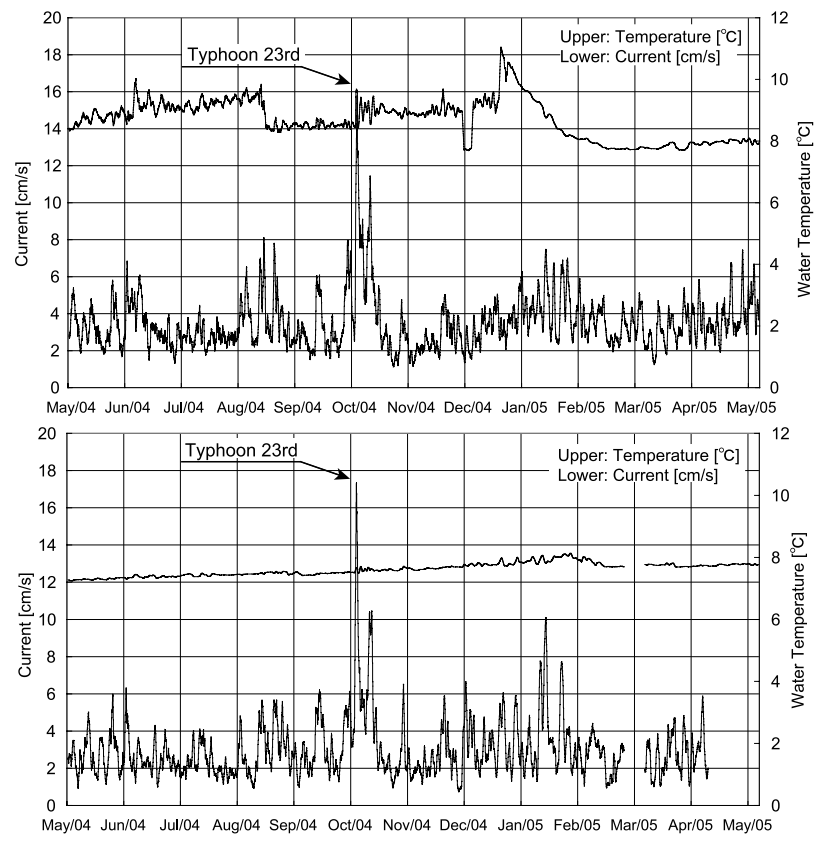

Fig. 4 Water current velocity and temperature calculated from running mean over 24 hours in each ACM (from May 2004 to May 2005)

cause of vertically well mixing. Therefore, vertical mixing could be enhanced by forced mixing due to strong wind and water sinking due to surface cooling during these periods. In 2004, a larger number of typhoons came to land on/around Lake Biwa than in 2003 (Table 1), and the number of landing of typhoons was greatly updated in the observed records since 1951. In these typhoons in 2004, typhoon 23rd gave the largest impacts on the bot- 


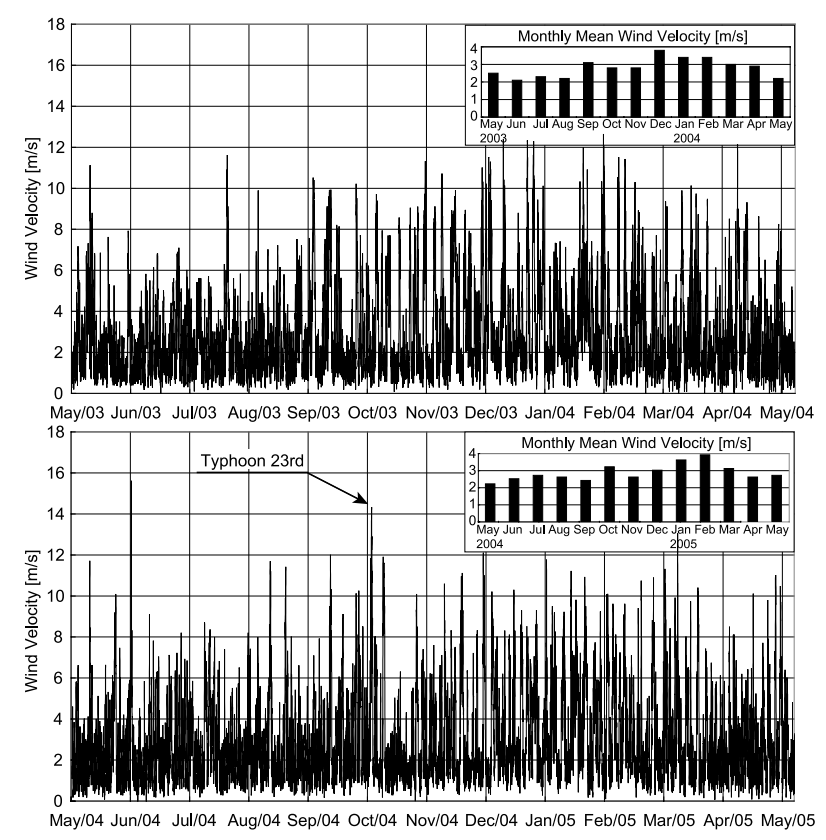

Fig. 5 Hourly and monthly mean wind velocity observed at Hikone Local Meteorological Observatory

Table 1 Typhoon landed near Lake Biwa in 2003 and 2004

\begin{tabular}{rrll}
\hline Year & No. & Period & Max Speed [m/s] \\
\hline 2003 & 10 & Aug/7-10 & 31.4 \\
2004 & 4 & Jun/11-13 & 17.2 \\
& 6 & Jun/19-21 & 36.4 \\
& 10 & Jul/28-Aug/2 & 22.3 \\
& 11 & Aug/4-5 & 15.4 \\
& 15 & Aug/18-20 & 19.4 \\
& 16 & Aug/29-31 & 26.6 \\
18 & Sep/6-8 & 28.3 \\
& 21 & Sep/29-30 & 23.1 \\
22 & Oct/9 & 10.8 \\
23 & Oct/20-23 & 28.5 \\
\hline
\end{tabular}

tom current in Lake Biwa (Fig. 4 (b)). Furthermore, water current was also relatively strong after typhoon 23rd was passed. During these periods, typhoon 24th approached to the Japan coast on the Pacific Ocean side, and relatively strong wind blew around the lake. This strong wind also gave large impacts on the bottom currents. Figure 6 shows raw data of the water current in both layers during the period of typhoon 23rd. In the figure, it is shown that strong mixing was generated at almost same time. However, no clear change was shown in the trend of water temperature. It means that this disturbance might not destroy the vertical structure of the water temperature. On the other hand, bottom stress largely increased during the typhoon 23rd period (Fig. 7), but it was not so large in August and September in 2004 although, a large number of typhoons landed near Lake Biwa (Table 1). This difference must be derived from the difference of duration and intensity of strong wind. Actually, strong wind brought by typhoon 23rd in 2004 might disturb bottom sediments. Furthermore, bottom stress during both mixing periods in winter
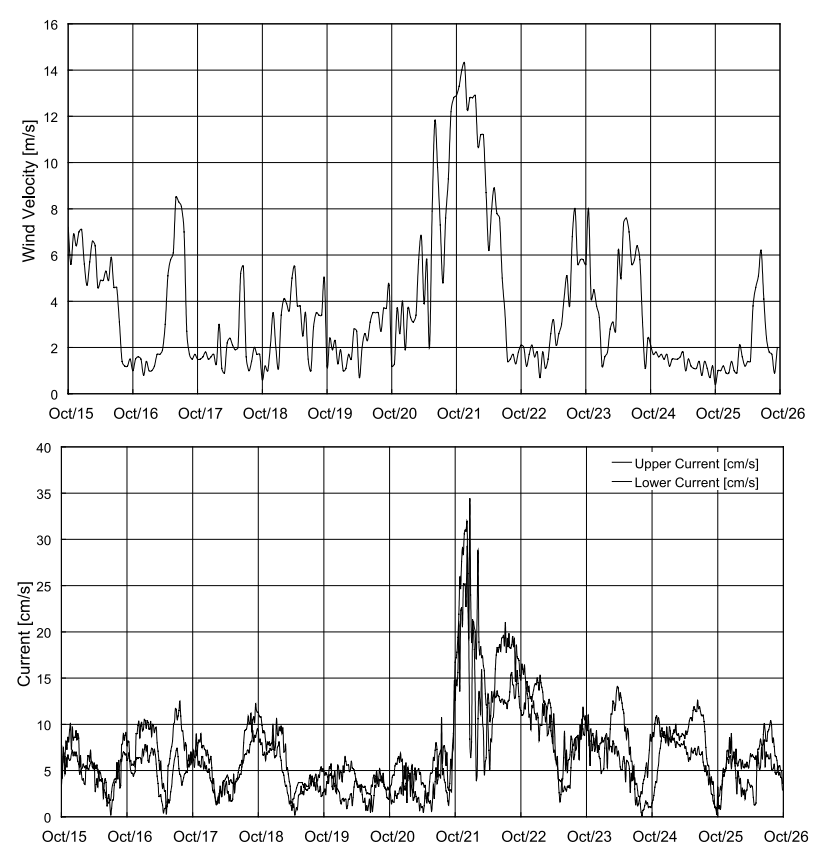

Fig. 6 Mean wind velocity (upper panel) and water current velocity (lower panel) during typhoon 23rd
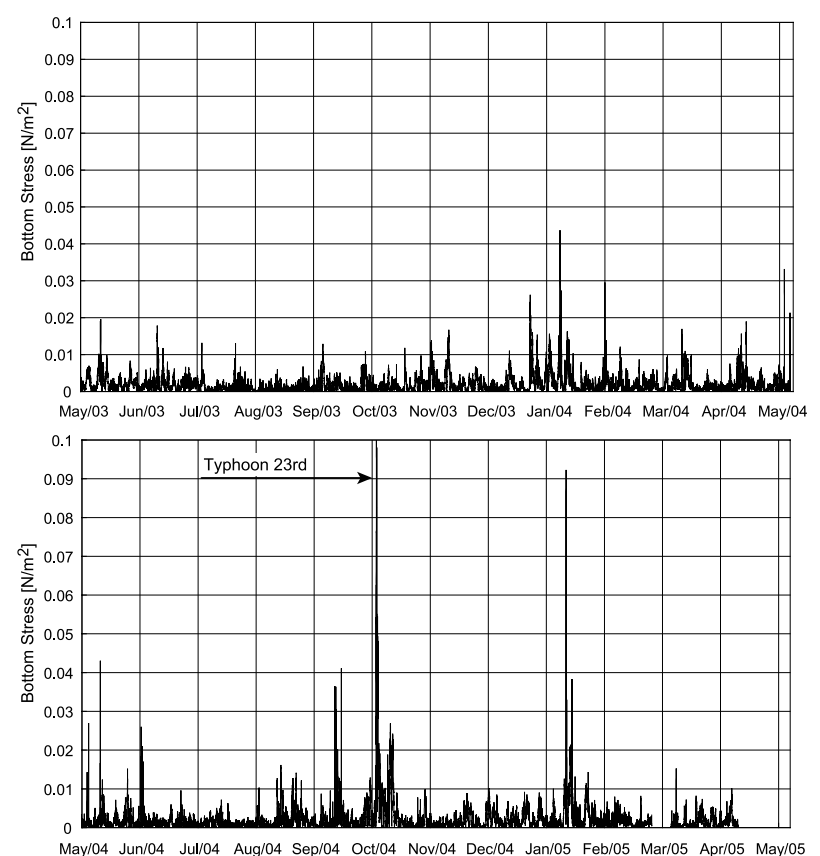

Fig. 7 Estimated bottom stress from May 2003 to May 2004 (upper panel) and from May 2003 to May 2004 (lower panel)

also increased. This means that vertical mixing in winter could increase bottom stress, and then it might enhance re-suspension of the bottom sediments, as well as strong wind due to typhoon in the end of stratification period.

We assumed that the sensor of the current meter near the lake bottom is approximately located in the turbulent boundary layer. In the study, it is difficult to calculate strictly the thickness of turbulent boundary layer because 
the data of water current was spatially limited. However, the lower limit of the turbulent boundary layer can be estimated in each measurement time. During the observation period, the lower limit values of the turbulent boundary layer were always less than $70 \mathrm{~cm}$ from lake bottom, and their mean value was about $5 \mathrm{~cm}$ from lake bottom. Therefore, the sensor position could be considered to be near or in the turbulent boundary layer in that sense. To develop further strict estimation of the thickness of turbulent boundary layer in the future, the measurement data about water current at multi layers of water column might be needed.

\section{Conclusion}

We showed the trends of water currents and temperature during last 2-years observations. Mean water current velocity was low as the previous study showed, but relatively strong currents caused by strong mixing were sometimes observed when the lake was weak stratified or unstratified. These strong currents enhanced the bottom stress, and then could disturb bottom sediments when the stress becomes over $0.1 \mathrm{~N} / \mathrm{m}^{2}$ as Kumagai ${ }^{(6)}$ suggested.

\section{References}

( 1 ) Suda, K., Seki, K., Ishii, J., Takaishi, S. and Mizuuchi, S., The Report of Limnological Observation in Lake Biwa (I), Bulletin of the Kobe Marine Observatory, (in Japanese), Vol.8 (1926), p.104.

( 2 ) Kumagai, M., Asada, Y. and Nakano, S., Gyres Measured by ADCP in Lake Biwa, Edited by Imberger, J., Physical Processes in Lakes and Oceans, Coastal and Estuarine Studies, American Geophysical Union, Washington, D.C., 54 (1998), pp.199-208.
( 3 ) Endoh, S., Yamashita, S., Kawakami, M. and Okumura, Y., Recent Warming of Lake Biwa Water, Japanese Journal of Limnology, (in Japanese), Vol.60 (1999), pp.223-228.

(4) Kumagai, M., Ishikawa, K. and Ishiguro, N., Impacts of Global Warming on Large Lakes, Edited by Franks, S., Blöschl, G., Kumagai, M., Musiake, K. and Rosbjerg, D., Water Resources Systems - Water Availability and Global Change, IAHS Red Book 280, (2003), pp.65-69.

( 5 ) Okumura, Y. and Endoh, S., Continuous Current Measurements in Lake Biwa I Method and Some Results, Japanese Journal of Limnology, (in Japanese), Vol.46 (1985), pp.135-142.

(6) Kumagai, M., Bottom Current in Northern Basin of Lake Biwa, Research Report from Lake Biwa Research Institute, (in Japanese), No.86-A04 (1986), pp.23-28.

( 7 ) Okumura, Y. and Endoh, S., Continuous Current Measurements in Lake Biwa III Results of Long-Term Observation over One Year, Japanese Journal of Limnology, (in Japanese), Vol.58 (1997), pp.293-303.

( 8 ) Kanari, S., Internal Waves and Seiches, Lake Biwa, Edited by Horie, S., (1984), pp.185-235, Dr. W. Junk Publishers.

(9) Lorke, A., Umlauf, L., Jonas, T. and Wüest, A., Dynamics of Turbulence in Low-Speed Oscillating Bottom-Boundary Layers of Stratified Basins, Environmental Fluid Mechanics, Vol.2 (2002), pp.291-313.

(10) Lars, U. and Ulrich, L., Interbasin Exchange and Mixing in the Hypolimnion of a Large Lake: The Role of Long Internal Waves, Limnology and Oceanography, Vol.50 (2005), pp.1601-1611.

(11) Gloor, M., Wüest, A. and Münnich, M., Benthic Boundary Mixing and Resuspension Induced by Internal Seiches, Hydrobiologia, Vol.284 (1994), pp.59-68. 